\title{
Avaliação da microcirculação cutânea na insuficiência venosa crônica - estudo crítico da utilização da técnica de imagem espectral por polarização ortogonal
}

\author{
Evaluation of cutaneous microcirculation in chronic venous insufficiency - \\ critical study using orthogonal polarization spectral imaging technology
}

\section{C arlos Eduardo Virgini-M agalhães*}

O bjetivos: Avaliar a utilização de uma nova tecnologia (imagem espectral por polarização ortogonal C ytoscan ${ }^{\circledR}$ ) na anál ise quantitativa da microangiopatia cutânea de portadores de insuficiência venosa crônica causada pela hipertensão venosa crônica, que ocorre precocemente na instalação das lesões tróficas na insuficiência venosa crônica e está intimamenteligada à sua gravidade, embora ainda seja completamente desconhecida da prática clínica.

Pacientes e métodos: C inqüenta e seis indivíduos do sexo feminino, representando um total de 112 membros inferiores, foram selecionados e divididos em seis grupos: C $1(n=21), C 2(n=20), C 3(n=17), C 4(n=18), C 5$ $(n=11)$ e grupo controle $(n=25)$. U tilizando o Cytoscan ${ }^{\circledR}$, foram medidos os seguintes parâmetros da microcirculação cutânea: (1) densidade capilar, (2) morfologia capilar, (3) diâmetro da papila dérmica, (4) diâmetro do novelo capilar e(5) diâmetro da al ça capilar. 0 sresultados foram comparados ao grupo controle e interpretados de acordo com a classificação CEAP.

Resultados: A morfologia capilar ( $P=0,028)$ e 0 diâmetro da al ça capilar ( $P=0,007)$ foram os parâmetros que se alteraram mais precocemente na insuficiência venosa crônica, havendo diferença estatística a partir de
C2 quando comparamos ao grupo controle. A densidade capilar é semelhante nos grupos controle, C 1, C2 e C 3, havendo redução do número de capilares apenas nos estágios mais avançados da insuficiência venosa crônica, com diferença estatística a partir de C $4(P=0,015)$. O s diâmetros do novelo $(P=0,001)$ e da papila dérmica $(P=0,039)$ tendem a aumentar conforme se avança na classificação CEAP, mostrando diferençaestatística quando comparados ao grupo controle a partir de C 3 . Esses achados representam a hipertrofia da papila dérmica encontradanalipodermatoscleroseem estágiosmaisavançados da insuficiência venosa crônica.

C onclusão: É possível quantificar objetivamente 0 grau de microangiopatia na insuficiência venosa crônica através do Cytoscan ${ }^{\circledR}$. D ois parâmetros figuram como os mais importantes para identificar diferenças significativas entre pacientes e controles nas fases iniciais da insuficiência venosa crônica: morfologia capilar e diâmetro do novelo capilar. A rarefação capilar, medida através da densidade capilar, só é identificável em fases tardias da insuficiência venosa crônica. A tecnologia de imagem espectral por polarização ortogonal é um método eficaze prático para a aquisição de imagens da microcirculação cutânea e suas al terações na insuficiência venosa crônica.

\footnotetext{
* Pós-graduação em Fisiopatologia Clínica e Experimental - CLINEX, Universidade do Estado do Rio de Janeiro (UERJ).

Orientadora: Prof ${ }^{a}$. Eliete Bouskela

Apresentação: 10/12/2004

Banca examinadora: Prof. Francisco Humberto de Abreu Maffei, Prof. Luis Felipe da Silva, Prof. Tony Verbeuren, Prof. Ruy Garcia Marques, Profa . Eliete

Bouskela.

Correspondência: Secretaria da Disciplina de Cirurgia Vascular - Hospital Universitário Pedro Ernesto

Boul. Vinte e Oito de Setembro, 77/448 - CEP 20551-030 - Rio de Janeiro, RJ - Tel.: (21) 2587.6822 - Fax: (21) 2264.1561 - E-mail: virgini@uerj.br

Resumo submetido em 19.09.05, aceito em 09.11.05.
} 